\title{
High-resolution Remote Sensing-based Method for Determining the Changes of Loss Risk from Earthquake-induced Geohazard-chain
}

\author{
Wenhua Qi \\ Institute of Geology \\ China Earthquake Administration \\ Beijing, China
}

\author{
Guiwu Su \\ Institute of Geology \\ China Earthquake Administration \\ Beijing, China
}

\begin{abstract}
Taking the year 1979, 2008 and 2010 as the representative reference periods, the vulnerabilities and loss risks of hazard-affected bodies from Wenchuan Earthquake-induced geohazard-chain and its temporal-spatial changes in Qingping country have been analyzed mainly through GIS, high-resolution remote sensing-based method and scenario analytical method. The main achievements are concluded as follows: From 1979 to 2010, the building area increased 2.4 times, the road mileage grew more than 2 times but the farmland area reduced by $40.7 \%$. Under the scenario of Wenchuan Earthquake-induced geohazard-chain, in the last thirty years, the damaged building area increased 2.7 times, the mileage of destroyed road grew 1.9 times but the ruined farmland decreased by $62.6 \%$. The economic losses of the three kinds of hazard-affected bodies in 2010 were 4.41 times more than that in 1979. Urbanization, population growth and economic development are the main driving forces of the temporal-spatial changes of the risk from earthquake-induced geohazard-chain in Qingping country.
\end{abstract}

Index Terms-high-resolution remote sensing, earthquakeinduced geohazard-chain, risk, the Qingping Country.

\section{INTRODUCTION}

Once major natural disaster occurred, it became prone to generate chain effect. A strong earthquake not only causes directly damage, but also can result in a serious of secondary disasters. The earthquake-induced geohazard-chain is a kind of special evolving form of mountain disaster chain under the action of earthquake. On May 12th, 2008, a great earthquake of Ms 8.0 hit Wenchuan County in Sichuan Province which induced a large number of geo-hazards in the form of landslide, rockfalls and debris flows and generated abundant unconsolidated material. With subsequent rainstorms later, the loose accumulation was transformed into debris flows. These geo-hazards have resulted in more than 20,000 deaths [1]. And these will be very active and cause considerable damages in the affected area over 10 30 years after the earthquake [2].

It is generally accepted that natural disaster is the result of the interaction of natural hazard and hazard-affected bodies. So this study preliminary analyzes the risk changes of earthquakeinduced geohazard-chain from the two aspects above taking Qingping country as an example. Firstly, this paper reveals the development process and influence zones of the earthquake- induced geohazard-chain and extracts the types and spatial distribution of the hazard-affected bodies. Secondly, through scenario analytical method, the temporal-spatial changes of the vulnerabilities and loss risks of hazard-affected bodies were analyzed. Finally, the driving factors which influence the temporal-spatial changes of the risk were discussed. These preliminary results can provide decision support for regional sustainable development of economy and ecological and environmental protection, especially be used for the risk and vulnerability study on earthquake and secondary geological disasters induced by large earthquake.

\section{MATERIALS AND METHODS}

\section{A. Study Site}

Qingping country in Mianzhu is located in the northwest of Sichuan basin, in central Longmen Mountains, lying between $31^{\circ} 29^{\prime} \sim 31^{\circ} 42^{\prime} \mathrm{N}$ latitude and $103^{\circ} 55^{\prime} \sim 104^{\circ} 9^{\prime} \mathrm{E}$ longitude. The study area is the typical high mountains and deep valleys landform and is characterized by humid subtropical climate. As its geological features, the area is vulnerable to earthquake and geo-hazards. And it is one of the most serious disaster areas after the Wenchuan earthquake which led to the deterioration of the geological environment [3].

\section{B. Data}

The high-resolution remote sensing images before and after Wenchuan Earthquake are used which include a QuickBird image in February 2008 and two WorldView-II images in February and December 2010. Their spatial resolution in the panchromatic band is $1 \mathrm{~m}$ and $0.5 \mathrm{~m}$, respectively. The Landsat MSS image in 1970s with a spatial resolution of $80 \mathrm{~m}$ and 1/50,000-scale topographic map of Qingping country are also utilized. In addition, statistics and archival data in 1970s, 2008 and 2010 are used in the study area.

\section{Methods}

1) Risk Assessment Based on High-resolution Remote Sensing and GIS.

The method includes two parts: the first part is extraction of disaster influence zones and hazard-affected objects attributes; the second part is calculation of disaster loss risk. This study 
takes buildings, roads and cultivated land as the geological hazard-affected objects.

\section{a) Extraction}

The extraction of the damage scope of disasters, roads and farmland adopts visual interpretation method. The cast shadows of buildings in high-resolution remote sensing images can reflect their three-dimensional attributes on spatial position and height. By the imaging theories of cast shadow, the attributes of buildings can be extracted. Its detail algorithm process was derived from the method of Qi et al [4-5].

\section{b) Calculation of Loss Risk}

The calculation formulas of disaster loss risk of three kinds of geological hazard-affected bodies are shown as follows:

$$
\begin{aligned}
& V=V_{b}+V_{r}+V_{c} \\
& V_{b}=\sum_{i}\left[S_{i} \cdot\left(P_{b i}+P_{d i}\right)\right] \\
& V_{y}=L_{y} \cdot P_{Y} \\
& V_{c}=S_{c} \cdot P_{g}
\end{aligned}
$$

Where $V$ is the loss of all three kinds of hazard-affected objects, yuan; $V_{b}, V_{r}$ and $V_{c}$ is the economic losses of damaged buildings, roads and farmland, respectively, yuan; $i$ is the building type; $S_{i}$ is the damage area of the buildings with ' $i$ ' type, $\mathrm{m}^{2} ; P_{b i}$ is the rebuilding cost per square meter of the buildings with ' $i$ ' type, yuan/ $\mathrm{m}^{2} ; P_{d i}$ is the value of indoor property per square meter of the buildings with ' $i$ ' type, yuan/ $\mathrm{m}^{2} ; L_{r}$ is the damaged mileage of road, $\mathrm{m} ; P_{r}$ is the rebuilding cost per meter of road, yuan/ $\mathrm{m} ; S_{c}$ is the damage area of farmland, $\mathrm{m}^{2} ; P_{s}$ is the value of farmland per square meter, yuan/ $\mathrm{m}^{2}$.

2) Scenario Analysis

Scenario analysis is a process of analyzing possible future events by considering alternative possible outcomes. But in this study, the time sequence is reversed. In other words, we assume the recent events occurred in a certain historical time, and then analyze the possible outcomes. There the Wenchuan earthquake-induced geohazard-chain is taken as a large disaster. Setting the scenario that the large geological disaster had occurred in 1979 and 2008, the damaged amount and economic losses are calculated in the two periods.

\section{3) Literature Analysis and Field Investigation}

By the analysis of a large number of literatures, the time series of earthquake-induced geo-hazards can be built. Then the phases of the high-resolution remote sensing images can be determined according to the time series. Through the field investigation the accuracy of the disaster time series and remote sensing images interpretation results can be checked.

\section{RESULTS}

\section{A. Geohazard-chain Induced by Wenchuan Earthquake in Qingping Country}

The Wenchuan earthquake-induced geohazard-chain in Qingping country consisted of a large scale rockslidesturzstrom at Wenjiagou valley occurred on 12th May 2008, group debris flows occurred on 24th September 2010 and group debris flows occurred on 13th August 2010. Before the Wenchuan earthquake, there was few debris flow in all the gullies (Fig. 1 A). But the earthquake led to the deterioration of the geological environment, and abundant unconsolidated material accumulated along slope and valleys that paved the way for geohazard-chain. Figure 1 shows the damage scope of the earthquake-induced geohazard-chain expanded from the east of the Mianyuan river to the west and the area of three geological hazards is $1.40 \times 10^{6} \mathrm{~m}^{2} 、 0.25 \times 10^{6} \mathrm{~m}^{2} 、 1.38 \times$ $10^{6} \mathrm{~m}^{2}$, respectively (Fig. $1 \mathrm{~B}$ ). The accumulated damage area had more than doubled from $1.40 \times 10^{6} \mathrm{~m}^{2}$ to $3.05 \times 10^{6} \mathrm{~m}^{2}$.
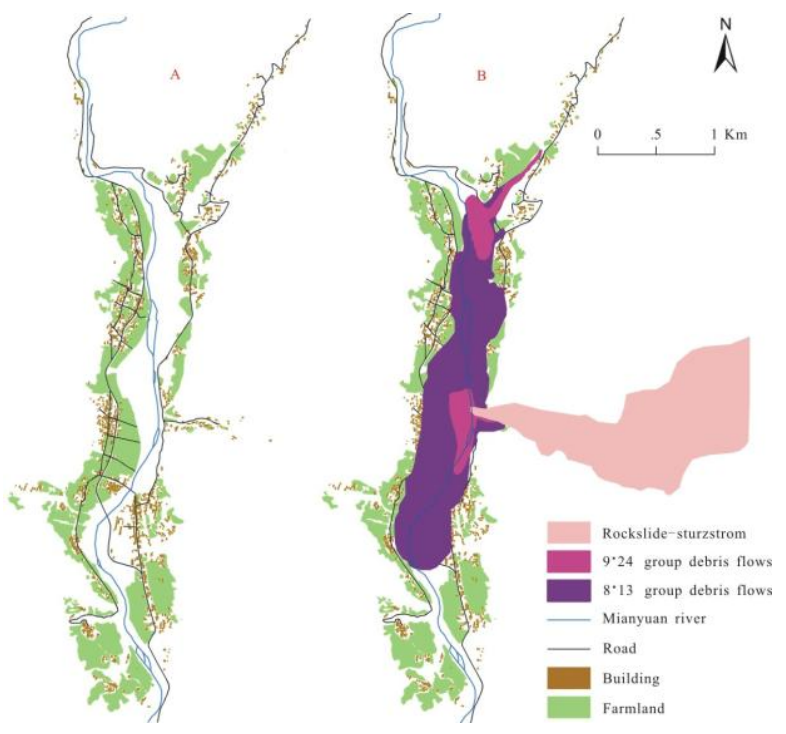

Fig. 1. Scope of the three earthquake-induced geo-hazards

\section{B. Exposure of Hazard-affected Objects}

In this paper buildings, roads and farmland were taken as the hazard-affected bodies. Based on high-resolution remote sensing and GIS technique, the exposed amount and spatial distribution of three kinds of hazard-affected bodies are extracted in the year of 1979, 2008 and 2010 (Table 1, Fig. 2).

TABLE I. EXPOSED AMOUNT OF THREE KINDS OF HAZARD-AFFECTED BODIES IN 1979, 2008 AND 2010

\begin{tabular}{|c|c|c|c|c|}
\hline \multirow{2}{*}{$\begin{array}{c}\text { Hazard- } \\
\text { affected } \\
\text { Body }\end{array}$} & \multirow{2}{*}{ Type } & \multicolumn{3}{|c|}{ Periods } \\
\cline { 3 - 5 } & & $\mathbf{1 9 7 9}$ & $\begin{array}{c}\text { Before } \\
\text { earthquake } \\
\text { in 2008 }\end{array}$ & 2010 \\
\hline \multirow{3}{*}{$\begin{array}{c}\text { Building } \\
\left(\mathrm{m}^{2}\right)\end{array}$} & 1-story & $20.3 \times 10^{4}$ & $11.7 \times 10^{4}$ & $10.2 \times 10^{4}$ \\
\cline { 2 - 5 } & 2-story & About 0 & $9.0 \times 10^{4}$ & $24.5 \times 10^{4}$ \\
\cline { 2 - 5 } & 3-story & 0 & $6.1 \times 10^{4}$ & $6.2 \times 10^{4}$ \\
\cline { 2 - 5 } & More than 3 & 0 & $0.9 \times 10^{4}$ & $7.9 \times 10^{4}$ \\
\hline \multirow{2}{*}{$\begin{array}{c}\text { Road } \\
(\mathrm{km})\end{array}$} & Main road & 7 & 13 & 17 \\
\cline { 2 - 5 } & Secondary road & 19 & 14 & 14 \\
\hline \multicolumn{2}{|c|}{ Farmland (m $\left.{ }^{2}\right)$} & $157.2 \times 10^{4}$ & $126.4 \times 10^{4}$ & $93.2 \times 10^{4}$ \\
\hline
\end{tabular}

Table 1 and Figure 2 shows the building area increased significantly from $20.3 \times 10^{4} \mathrm{~m}^{2}$ in 1979 to $48.8 \times 10^{4} \mathrm{~m}^{2}$ in 2010 
by 2.4 times which mainly occurred in the period from 2008 to 2010 because of the post-earthquake reconstruction. In building story and structure type respect, most of the buildings in the year of 1979 were single-story brick; before Wenchuan earthquake in 2008 the buildings were mainly 1-story and 2story and the proportion of the two kinds of buildings was $42.2 \%$ and $32.5 \%$ respectively. The buildings in 2010 were still mainly 1-story and 2-story, but the proportion of buildings with two stories became more. In addition, buildings with four stories or more increased largely from $0.9 \times 10^{4} \mathrm{~m}^{2}$ in 2008 to $7.9 \times 10^{4} \mathrm{~m}^{2}$ in 2010 by nine times. The total main road mileage increased from $7 \mathrm{~km}$ in 1979 to $17 \mathrm{~km}$ in 2010 by more than 2 times. But in the last 30 years there was a 40.7 percent decreased in farmland area which reduced from $157.2 \times 10^{4} \mathrm{~m}^{2}$ to $93.2 \times 10^{4} \mathrm{~m}^{2}$.

\section{Loss Risk Evaluation}

Employed the scenario analysis method, the loss risks of hazard-affected bodies from Wenchuan earthquake-induced geohazard-chain were analyzed in Qingping country.

1) Amount of Damaged Hazard-affected Bodies

Under the scenario of earthquake-induced geohazard-chain, the damaged area of buildings in the year of 1979, 2008 and 2010 was $4.7 \times 10^{4} \mathrm{~m}^{2}, 7.6 \times 10^{4} \mathrm{~m}^{2}$ and $12.7 \times 10^{4} \mathrm{~m}^{2}$ respectively (Table 2). The damaged building area in 2010 was 2.7 times more than that in 1979. The damaged mileage of roads increased from $4.8 \mathrm{~km}$ in 1979 to $9 \mathrm{~km}$ in 2010 by 1.88 times. But there was a 62.6 percent decrease in ruined farmland area which reduced from $36.6 \times 10^{4} \mathrm{~m}^{2}$ to $13.7 \times 10^{4} \mathrm{~m}^{2}$ in the last 30 years.

TABLE II. THE AMOUNT OF DAMAGED HAZARD-AFFECTED BODIES UNDER SCENARIO IN THREE PERIODS

\begin{tabular}{|c|c|c|c|}
\hline \multirow{2}{*}{$\begin{array}{c}\text { Hazard-affected } \\
\text { Body }\end{array}$} & \multicolumn{3}{|c|}{ Periods } \\
\cline { 2 - 4 } & $\mathbf{1 9 7 9}$ & $\begin{array}{c}\text { Before } \\
\text { earthquake } \\
\text { in 2008 }\end{array}$ & $\mathbf{2 0 1 0}$ \\
\hline building $\left(\mathrm{m}^{2}\right)$ & $4.7 \times 10^{4}$ & $7.6 \times 10^{4}$ & $12.7 \times 10^{4}$ \\
\hline road $(\mathrm{km})$ & 4.8 & 7.0 & 9.0 \\
\hline farmland $\left(\mathrm{m}^{2}\right)$ & $36.6 \times 10^{4}$ & $25.3 \times 10^{4}$ & $13.7 \times 10^{4}$ \\
\hline
\end{tabular}

\section{2) Loss Risk}

Under the scenario of earthquake-induced geological hazard chain, the loss risk of the hazard-affected objects in the year of 1979, 2008 and 2010 was 37.25 million, 87.3 million and 164.15 million respectively (Table 3 ). The economic loss risk in 2010 was 4.41 times more than that in 1979. In proportional composition respect, the proportion of economic loss of building, road and farmland was $63.1 \%, 7.4 \%$ and $29.5 \%$ of the total in 1979 , respectively. That was $91.5 \%, 4.3 \%$ and $4.2 \%$ of the total in 2010, respectively. From 1979 to 2010, the loss risk of buildings was becoming increasingly high, but the loss risk of cultivated land was the opposite which was getting lower and lower.
TABLE III. THE LOSS RISK OF HAZARD-AFFECTED BODIES UNDER SCENARIO IN THREE PERIODS

\begin{tabular}{|c|c|c|c|}
\hline \multirow{2}{*}{ Hazard-affected Body } & \multicolumn{3}{|c|}{ Periods } \\
\cline { 2 - 4 } & $\mathbf{1 9 7 9}$ & $\begin{array}{c}\text { Before } \\
\text { earthquake } \\
\text { in 2008 }\end{array}$ & $\mathbf{2 0 1 0}$ \\
\hline building (million yuan) & 23.50 & 69.30 & 150.30 \\
\hline road (million yuan) & 2.77 & 5.35 & 7.00 \\
\hline farmland (million yuan) & 10.98 & 12.65 & 6.85 \\
\hline total (million yuan) & 37.25 & 87.30 & 164.15 \\
\hline
\end{tabular}

\section{CONCLUSION AND DISCUSSION}

Based on the high-resolution RS and GIS technique, utilized scenario analytical method, the vulnerabilities and loss risks of hazard-affected bodies from Wenchuan Earthquakeinduced geohazard-chain and its temporal-spatial changes in Qingping country have been analyzed. From 1979 to 2010, the building area increased 2.4 times, the road mileage grew more than 2 times but the cultivated land area reduced by $40.7 \%$. Under the Wenchuan Earthquake-induced geohazard-chain scenarios, in the last thirty years, the damaged building area increased 2.7 times, the mileage of destroyed road grew 1.9 times but the ruined farmland decreased $62.6 \%$. The economic losses of the three kinds of hazard-affected bodies in 2010 were 4.41 times more than that in 1979.

Urbanization, population growth and economic development are the main driving forces of the temporal-spatial changes of the earthquake-induced geohazard-chain risk in Qingping country. With the rapid development of urbanization and population growth, the human being's engineering activities are intense more and more and expand to the area liable to geological disasters, such as deposition fan of debris flow, landslide accumulation body, riverway. This kind of urban construction which has gone beyond the geological environment carrying capacity makes hazard-affected bodies become more exposed to hazardous conditions. So with the urbanization and population growth the loss risks from earthquake-induced geological disaster would increase. With the fast development of socio-economy country and improvement of living standards, the economic and functional value of hazard-affected bodies increases largely. The rise of value results in that the economic vulnerabilities of hazardaffected bodies increase too. Thus, once the geo-hazard with the same intensity and scale occurred, the loss risks of all kinds of hazard-affected bodies would be more and more.

\section{ACKNOWLEDGMENT}

This study was financially supported by the National Natural Science Foundation of China under grant No. 40971274 (Differences of Human's Awareness of and Response to Earthquake Disasters in the Regional and the Local Scales-Case Studies from the Recent Earthquake Events within Mainland China).

\section{REFERENCES}

[1] Ping Sun, Yongshuang Zhang, Jusong Shi, Liwei Chen, "Analysis on the Dynamical Process of Donghekou RockslideDebris Flow Triggered by 5.12 Wenchuan Earthquake," Journal 
of Mountain Science. 2011, 8:140-148. Doi:10.1007/s11629011-2112-9.

[2] Hong Xie, Dunlun Zhong, Zhen Jiao, Jinshan Zhang. Debris flow in Wenchuan Earthquake-hit area in 2008. Journal of Mountain Science. 2009, 27(4): 501-509. (in Chinese)

[3] Huayong Ni, Wanmo Zheng, Yeqi Tang, Dewei Wang, Xuyu Chen, Ruge $\mathrm{Xu}$, Zhi Song. Formation, characteristics and trend of the group debris flows occurred on August 13 in Qingping, Mianzhu County. Hydrogeology \& Engineering Geology. 2011, 38(3): 129-133, 138. (in Chinese)

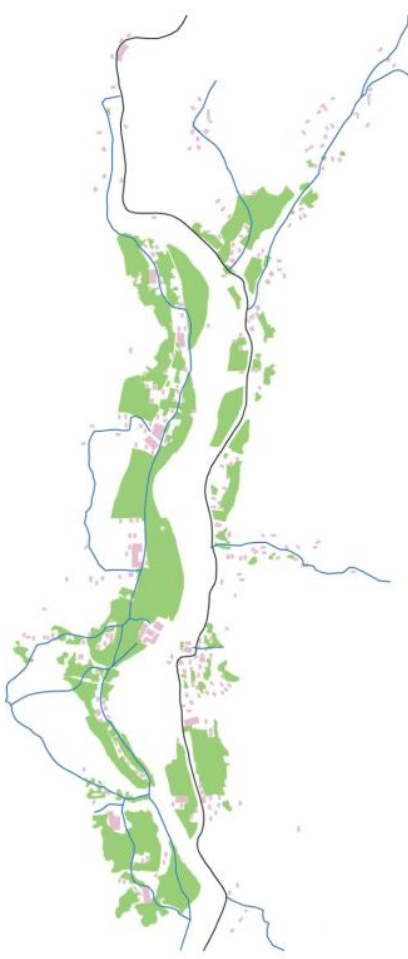

A 1979

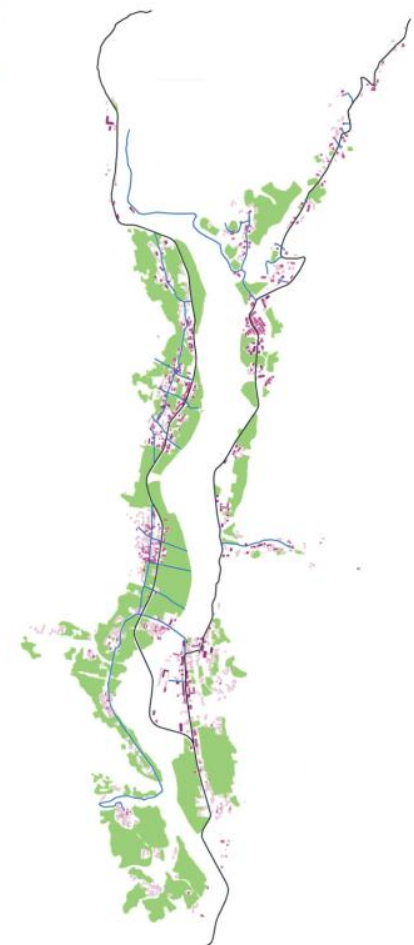

B before earthquake in 2008

[4] Wenhua Qi, Guiwu Su, Suling Zhang, Xinsheng Liu, Bengyong Wei. A pilot research on high-resolution remote sensing-based method for determining the vulnerabilities and loss risk from seismic disaster of building groups and its application: Taking the buildings in Tangshan peri-urban zones as examples. Earthquake Research in China. 2012(a), 28(1): 88 99. ( in Chinese)

[5] Wenhua Qi, Guiwu Su, Suling Zhang, Xinsheng Liu, Bengyong Wei, Lei Sun. Study on the changes of vulnerability and loss risk of buildings from seismic disaster in the process of urbanization - a case study of Tangshan area. Seismology and Geology. 2012(b), 34(4): 820 834. ( in Chinese )

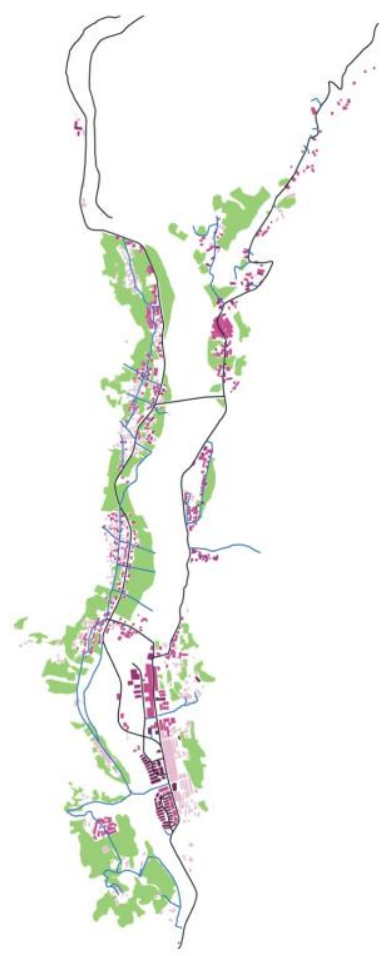

C February in 2010

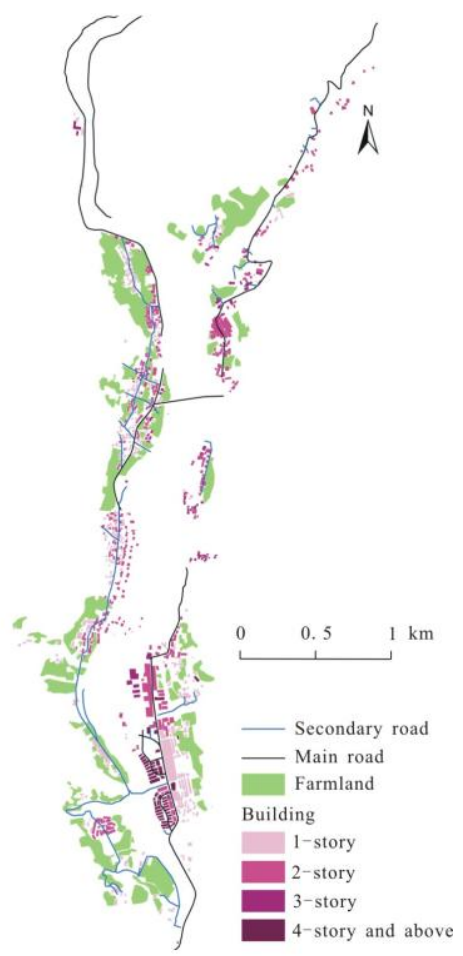

D December in 2010

Fig. 2. Distribution of the three kinds of hazard-affected objects in different periods 